\title{
Stem Cell Factor Gene Overexpression Enhances the Fusion Potential of Rat Bone Marrow Mesenchymal Stem Cells with Cardiomyocytes
}

\author{
Kanwal Haneef ${ }^{1,2}$, Rakhshinda Habib ${ }^{\mathbf{1 , 3}}$, Nadia Naeem ${ }^{1,3}$ and Asmat Salim ${ }^{1, *}$
${ }^{1}$ Dr. Panjwani Center for Molecular Medicine and Drug Research, International \\ Kanwal Haneef ${ }^{\mathbf{1}, \mathbf{2}}$, Rakhshinda Habib ${ }^{\mathbf{1 , 3}}$, Nadia Naeem $^{\mathbf{1 , 3}}$ and Asmat Salim ${ }^{\mathbf{1} *}$
${ }^{1}$ Dr. Panjwani Center for Molecular Medicine and Drug Research, International \\ Center for Chemical and Biological Sciences, University of Karachi, Karachi \\ ${ }^{2}$ Dr. Zafar H. Zaidi Center for Proteomics, University of Karachi, Karachi-75270 \\ ${ }^{3}$ Dow Research Institute of Biotechnology and Biomedical Sciences, Dow \\ University of Health Sciences, Ojha Campus, Gulzar-e-Hijri, SUPARCO Road, \\ KDA Scheme-33, Karachi
}

\begin{abstract}
A B S T R A C T
Cardiovascular disorders are major cause of death globally. Regeneration of cardiac tissue with the use of stem cells has appeared as an effective cell-based therapeutic option. Mesenchymal stem cells (MSCs) are the potential candidates for cell therapy due to their ease of isolation, proliferation, anti-apoptotic and proangiogenic properties. MSCs have the ability to fuse with somatic cells in vivo and depending upon the microenvironment, the fusion products may perform tissue-specific function. Stem cell factor (SCF) is one of the important cytokine for cardiomyocyte survival following cardiac injury. The main objective of the present study is to determine the fusion potential of SCF transfected MSCs and cardiomyocytes (CMs). Rat bone marrow MSCs were transfected with SCF through retroviral system and co-cultured with rat CMs. Co-culture of SCF transfected MSCs and CMs have shown increased number of fused cells $(\mathrm{P}<0.05)$ as compared to that in case of normal MSCs. This study suggests a potential role of SCF in enhancing the fusion potential of MSCs which may possibly improve the efficiency of MSCs for myocardial diseases.
\end{abstract}

\section{INTRODUCTION}

$\mathrm{H}$ eart diseases are one of the main causes of morbidity and mortality all over the world particularly in developing countries (Lachtermacher et al., 2010; Herrmann et al., 2011; Abdelwahid et al., 2016). The pathological mechanisms aiding in cardiac arrest consists of cardiomyocyte death, necrosis, cardiomyocyte hypertrophy, reduced contractility, inflammation and oxidative stress (Burchfield and Dimmeler, 2008; Steven et al., 2019). The discovery of differentiation potential of stem cells, which are unspecialized cells and capable of differentiating into specialized cell type, has opened new horizons in the field of regenerative medicine (Ioannidou, 2006; Keshtkar et al., 2018). However, as the injured myocardium is commonly ischemic with the scar formation, stem cell transplantation to the infarcted heart encountered many challenges and majority of the engrafted cells die due to lack of support and inaccessibility of nutrient

\footnotetext{
Corresponding author: asmat.salim@iccs.edu 0030-9923/2021/0006-2305 \$ 9.00/0

Copyright 2021 Zoological Society of Pakistan
}

and oxygen. So far several strategies have been adopted to improve the survival of engrafted cells and their resistance to oxidative stress (Abdelwahid et al., 2016).

Mesenchymal stem cells (MSCs) are nonhematopoietic cells and are adherent heterogeneous multipotent stem cell originated from mesoderm. Characteristically, these cells have perivascular residence where they contribute in the maintenance of other cell types and tissues (Psaltis et al., 2008). MSCs seem to reduce cardiac injury, as having potential to regenerate myocardium (Vertesaljai et al., 2008). MSCs engrafted into the injured heart may possibly acquire the cardiac cell characteristics which suggest that MSCs differentiation perhaps is associated with ischemic microenvironment therefore cardiac microenvironment might be a key factor in mesenchymal stem cell differentiation (Shim et al., 2004; Xie et al., 2006). Paracrine factors, for instance, cytokines and growth factors are generally produced by cardiac endogenous cells in response to stress and injury. These soluble molecules possibly function through paracrine signaling to facilitate stem cell mobilization from bone marrow or tissue to the place of damage, in this way promoting tissue regeneration (Witman et al., 2019). 
MSCs are capable of regulating different types of cells in their vicinity by means of direct cell to cell contact or communication and also via secretion of a broad range of soluble growth factors and cytokines (Fan et al., 2020).

Stem cell factor (SCF), also known as Steel factor or c-kit ligand, aids in the mobilization of stem cells towards the site of injury (Xu et al., 2007; Xiang et al., 2009). c-kit is a tyrosine kinase receptor expressed in stem cells and progenitor cells including stromal cells (Smith et al., 2001). SCF plays pivotal role in proliferation, survival and migration of stem cells through p38 MAPK pathway (Kuang et al., 2008; Mazzoldi et al., 2019). Functional cardiac regeneration and repair has been observed after myocardial infarction following implantation of MSCs, which is further enhanced by SCF (Fazel et al., 2005). It has been reported that $\mathrm{SCF}-\mathrm{c}$-kit pathway provides protection against cardiovascular diseases (Wigren et al., 2016). In a recent study, the role of SCF and its c-kit receptor for neovascularization has been explored. It was observed that hypoxic treatment of human endothelial cells results in increased expression of c-kit receptor in endothelial cells (Kim et al., 2019).

In the present study, we analyzed the myogenic potential of bone marrow MSCs virally transduced with SCF after co-culturing these cells with cardiomyocytes (CMs) at different time periods. Co-culture studies were performed to observe the fusion potential of SCF transduced MSCs and CMs. This study is an attempt to provide insight into designing of improved cell based therapeutic approach for cardiac diseases.

\section{MATERIALS AND METHODS}

\section{Animals}

International guidelines for the care and use of laboratory animals were followed for all animal procedures after the approval from the local ethical committee. Throughout the study, Sprague Dawley (SD) rats of both sexes weighing 200-300 g were used.

\section{Cell culture}

MSCs were isolated from SD rats. Tibia and femur were aseptically removed. DMEM supplemented with $10 \%$ fetal bovine serum (FBS), 100 unit $/ \mathrm{mL}$ penicillin, $100 \mu \mathrm{g} / \mathrm{mL}$ streptomycin, $1 \mathrm{mM}$ sodium pyruvate and 4 $\mathrm{mM} \mathrm{L}$-glutamine was flushed down the cavities of the bones. Culture was maintained at $37^{\circ} \mathrm{C}$ in a humidified atmosphere containing $5 \% \mathrm{CO}_{2}$. After 4 to 5 days, non adherent hematopoietic cells were removed. MSCs were isolated by their ability to adhere to the plastic surface. Fresh medium was provided after every 3 days. Cells were subjected to sub-culture when they reached approximately
$70 \%$ confluency. MSCs of passages 1-2 ( $\mathrm{P} 1$ or $\mathrm{P} 2$ ) were used throughout the study.

Cultures of neonatal CMs were prepared from the ventricles of 1-2 day old SD rats. Whole hearts were excised from 1 day old rat pups and immediately transferred into ice-cold PBS, followed by sterile ice cold balanced salt solution (20 mM HEPES-NaOH; pH 7.6, $130 \mathrm{mM} \mathrm{NaCl}, 1$ $\mathrm{mM} \mathrm{NaH} \mathrm{PO}_{4}, 4 \mathrm{mM}$ glucose, $3 \mathrm{mM} \mathrm{KCl}$ ). Ventricles were excised and minced in $0.05 \%$ trypsin-EDTA. Cells were digested in $0.5 \%$ trypsin-EDTA at $37^{\circ} \mathrm{C}$ and centrifuged at $3,500 \mathrm{rpm}$ for $10 \mathrm{~min}$ at $4^{\circ} \mathrm{C}$. Cell pellet was resuspended in a maintenance medium containing DMEM / F12 (1:1) supplemented with FBS $(20 \%)$, penicillin $(100 \mathrm{U} / \mathrm{mL})$, streptomycin $(100 \mathrm{mg} / \mathrm{mL})$ and bovine insulin $(1 \mu \mathrm{g} / \mathrm{mL})$. Cells were sub-cultured when they reached approximately $70 \%$ confluence. CMs of passages 1-2 (P1 or P2) were used throughout the study.

\section{Characterization of MSCs and CMs}

MSCs and CMs were analyzed by specific antibodies against CD44 (BD pharmingen), Thy-1 or CD90 (Cederlane International), c-kit or CD117 (Zymed Laboratiores), actin (sigma) and cardiac troponin T (Santa Cruz) by immunocytochemistry as previously described (Haneef et al., 2014). Cells were photomicrographed under fluorescence microscope (Eclipse TE 2000-S, Nikon, Japan).

\section{Transfection of MSCs with SCF gene \\ Retroviral vector construction}

PLXIN retroviral vectors containing SCF cDNA were custom synthesized by Clonetex systems Inc, USA. The 5' LTR promoter controls the expression of SCF and neomycin resistant genes of PLXIN-NeoR/SCF retroviral vectors derived from Moloney murine leukemia virus (MoMuLV).

\section{Packaging of recombinant retrovirus}

Retrovirus packaging cell line PT67 (CRL-12284) was purchased from American Type Culture Collection (ATCC), USA. Prior to transfection, PT67 cell line was seeded in $75 \mathrm{~cm}^{2}$ flask in DMEM supplemented with $10 \%$ FBS, $1 \mathrm{mM}$ sodium pyuvate, $4 \mathrm{mM}$ L-glutamine, $100 \mathrm{U} /$ $\mathrm{mL}$ penicillin and $100 \mu \mathrm{g} / \mathrm{mL}$ streptomycin. When cells reached $50-60 \%$ confluence, they were transfected with PLXIN-NeoR/SCF retroviral vector by using calcium phosphate kit (Stratagene, USA) according to the manufacturer's instructions. Cells were incubated for 17 h at $37^{\circ} \mathrm{C}$ using air jacketed $\mathrm{CO}_{2}$ incubator. Medium was aspirated and cells were washed twice with $5-10 \mathrm{~mL}$ of $\mathrm{Ca}^{++}$and $\mathrm{Mg}^{++}$free PBS. Cells were provided with $10 \mathrm{~mL}$ of antibiotic-free DMEM supplemented with 10\% FBS 
and incubated for $48 \mathrm{~h}$ at $37^{\circ} \mathrm{C}$ in $\mathrm{CO}_{2}$ incubator. Medium was transferred to a $15 \mathrm{~mL}$ falcon tube and centrifuged at $4500 \mathrm{x} \mathrm{g}$ for $10 \mathrm{~min}$. Viral supernatant was collected and filtered through $0.45 \mu \mathrm{m}$ filter and stored at $-80^{\circ} \mathrm{C}$ or used immediately for infection.

\section{Infection of mesenchymal stem cells}

MSCs were infected twice with viral supernatant diluted at a ratio of $1: 1$ with $F B S$-free and antibiotics-free DMEM. $10 \mathrm{~mL}$ of diluted viral supernatant was added into a $75 \mathrm{~cm}^{2}$ flask and incubated for $7 \mathrm{~h}$ at $37^{\circ} \mathrm{C}$ in $\mathrm{CO}_{2}$ incubator. Viral supernatant was removed and replaced with $10 \mathrm{~mL}$ of antibiotic-free DMEM supplemented with $10 \%$ FBS to stop transfection and incubated for further $24 \mathrm{~h}$ at $37^{\circ} \mathrm{C}$ in $\mathrm{CO}_{2}$ incubator. Medium was removed and MSCs were re-infected with viral supernatant and incubated for $4 \mathrm{~h}$ under same conditions. Viral supernatant was removed and replaced with $10 \mathrm{~mL}$ of antibiotic-free DMEM supplemented with 10\% FBS and incubated for 48 h, 1 week, 2 weeks and 3 weeks under same conditions. Fresh Medium was provided after every 3 days.

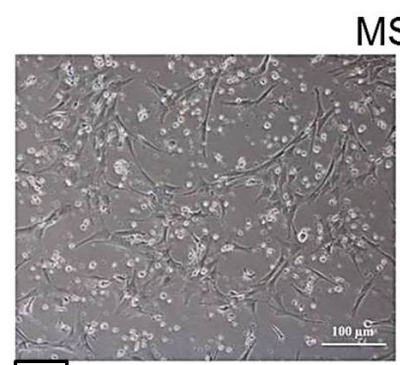

A $\quad$ PO
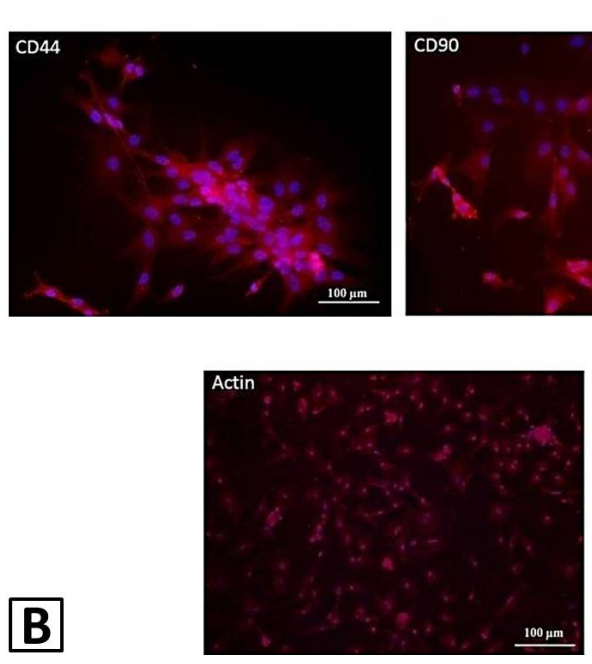

MSCs

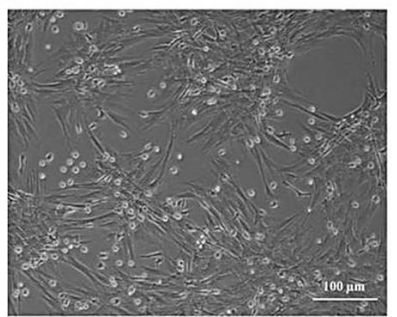

P1

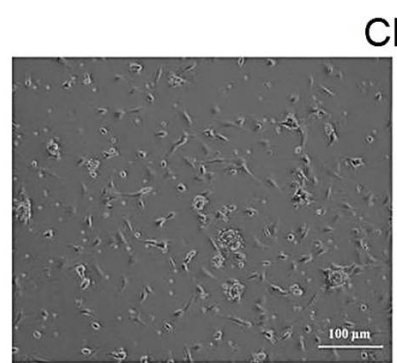

PO

MSCs
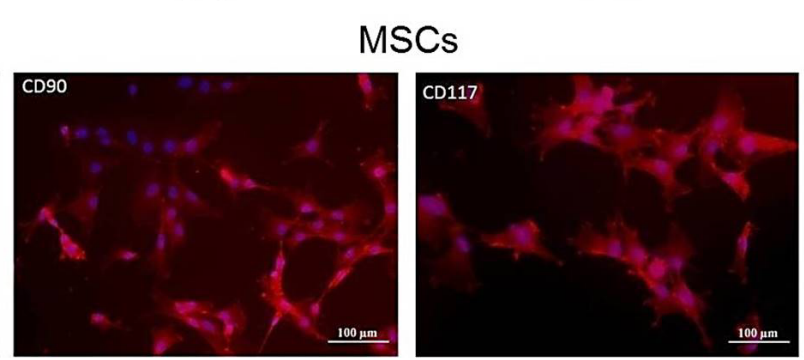

\section{$\mathrm{CMs}$}

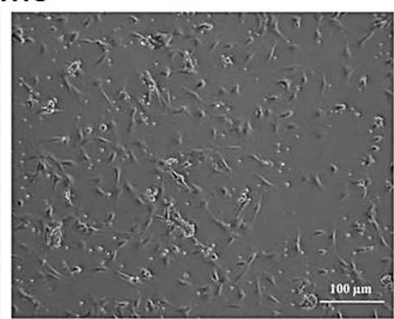

P1

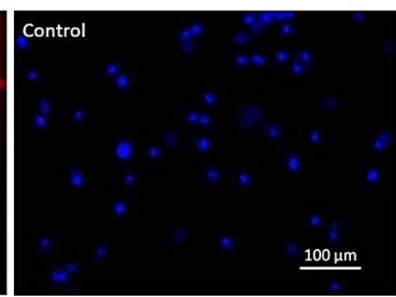

CMs
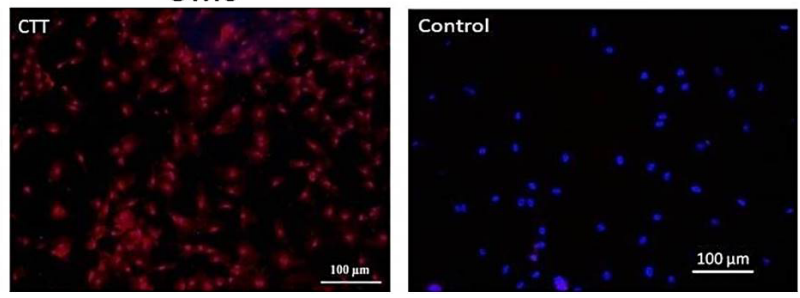

Fig. 1. Morphology and charachterization of MSCs and CMs: (A) Morphology of rat bone marrow MSCs and rat CMs at passage 0 (P0) and passage 1. Images were taken under phase contrast at 10X magnification; (B) Characeterization of rat bone marrow MSCs and rat CMs. MSCs were treated with specific primary antibodies against CD44, CD90, and CD117. CMs were treated with specific primary antibodies against actin, and cardiac troponin T. Alexa fluor 546 secondary antibody was used for detection and DAPI was used for nuclei staining. Images were taken under fluorescence microscope.

Table I.- Primer sequence, annealing temperature and expected product size.

\begin{tabular}{lllcc}
\hline Gene & Accession No. & Primer sequence & Annealing temp. $\left({ }^{\circ} \mathbf{C}\right)$ & Product size (bp) \\
\hline GAPDH & BC09593 & F: 5'-GGAAAGCTGTGGCGTGATGG-3' & 60 \\
& & R: 5'-GTAGGCCATGAGGTCCACCA-3' & 414 \\
SCF & NM- 021843.2 & F: 5'-CAAAACTGGTGGCGAATCTT-3' & 56 & 217 \\
& & R: 5'-GCCACGAGGTCATCCACTAT-3' & & \\
\hline
\end{tabular}




\section{RT-PCR}

Isolation of total RNA (treated and control groups) was carried out by using RNeasy Mini kit (74904, Qiagen) according to the manufacturer's protocol. One (1) $\mu \mathrm{g}$ of RNA was utilized for reverse transcription using the Superscript RT kit (18080-051, Invitrogen) and then amplified using oligonucleotide primer corresponding to stem cell factor (SCF) gene. Rat GAPDH gene was used as an internal control. Both primer sequences along with the expected product sizes and annealing temperatures are listed in Table I. Reversed transcribed products were denatured for $1 \mathrm{~min}$ at $94^{\circ} \mathrm{C}$, followed by 35 cycles of amplification i.e. denaturation at $94^{\circ} \mathrm{C}(1 \mathrm{~min})$, annealing at $56-60^{\circ} \mathrm{C}(1$ $\mathrm{min})$, and extension at $72^{\circ} \mathrm{C}(1 \mathrm{~min})$, and a final extension at $72^{\circ} \mathrm{C}$ for $10 \mathrm{~min}$. PCR product was subjected to be resolved on $1 \%$ agarose gel through gel electrophoresis. The integrated band density of SCF gene was normalized with the corresponding GAPDH band density and compared with the control group using gel documentation system (Alpha Innotech, FluorChemTM, USA).

\section{Co-culture studies}

Co-culture of SCF transfected MSCs and CMs were performed for the analysis of fusion potential of transfected MSCs with normal CMs. $48 \mathrm{~h}$ transfected MSCs were used in all experiments. Prior to co-culture, cells were treated with cell labeling dyes, PKH26 and PKH67 to label transfected MSCs and CMs, respectively according to the manufacturer's instructions. Cells were co-cultured for 15 days and analyzed by fluorescence microscope and flow cytometer.

\section{Statistical analysis}

Statistical analysis was performed by using one way ANOVA and bonferroni's post hoc test for multiple comparisons. Data is presented as means \pm standard error of mean (SEM). $\mathrm{p}<0.05$ was considered statistically significant.

\section{RESULTS}

\section{Characterization of isolated MSCs and CMs}

MSCs at passage 0 ( $\mathrm{P} 0)$ showed heterogonous population of cells, while at passage 1 (P1), MSCs predominately showed homogeneous population of cells with fibroblast-like morphology (Fig. 1A). P0 CMs showed heterogonous population of cells, while P1 CMs showed adherent spindle shaped population of cells (Fig. 1A). Immunocytochemistry analysis of rat bone marrow MSCs showed the presence of mesenchymal markers, CD44, CD90 and CD117 cell surface markers, as shown in our previous study (Haneef et al., 2014) (Fig. 1B). CMs showed positive expression of cardiac specific proteins, actin and cardiac troponin T (Fig. 1B).

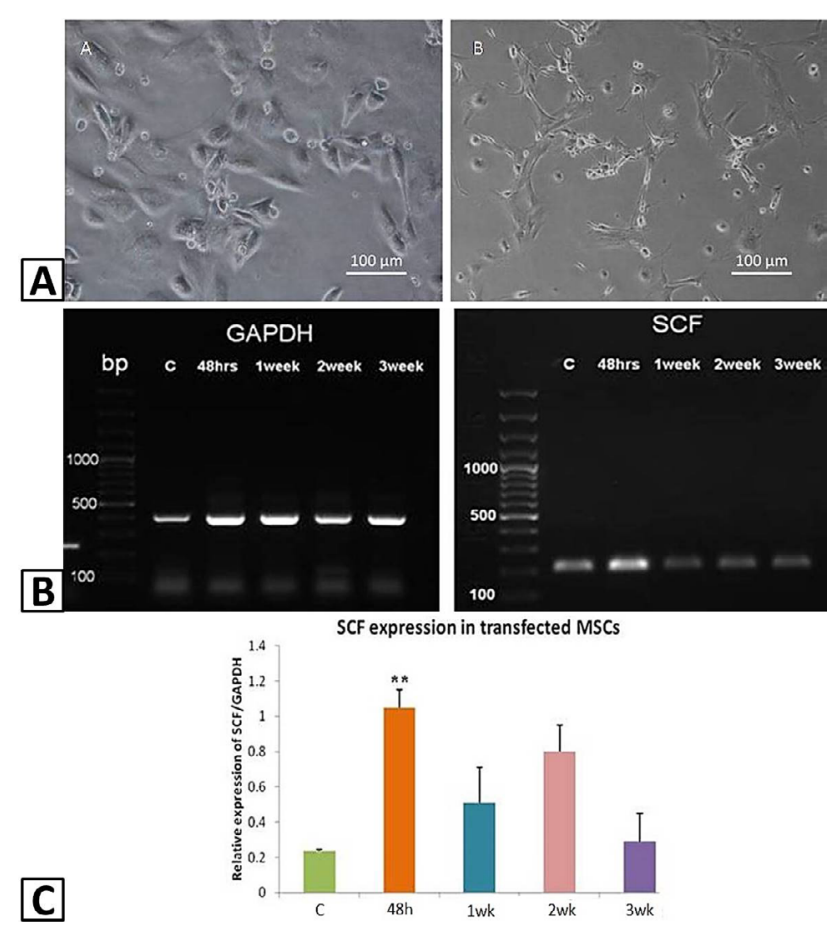

Fig. 2. Transfection of MSCs with SCF: (A) Morphology of MSCs before and after transfection with SCF. Images were taken under phase contrast at $10 \mathrm{X}$ magnification; (B) Gene expression analysis of SCF transfected MSCs. RT-PCR gel showing gene expression levels of GAPDH and SCF after transfection. Lane 1: DNA marker (100 to $1500 \mathrm{bp}$ ); Lane 2 -5: SCF expression in normal MSCs, and SCF transfected MSCc after 48 h, 1 week, 2 weeks and 3 weeks, respectively. (C) Corresponding bar diagram with quantitative analysis of SCF expression in normal and transfected MSCs. Results are expressed as Mean \pm $\operatorname{SEM}(\mathrm{n}=3)$. Differences between groups with $\mathrm{P}<0.05$ is considered statistically significant where $* \mathrm{P}<0.05$, ** $\mathrm{P}<$ 0.01 , and $* * * \mathrm{P}<0.001$.

\section{Transfection of MSCs with SCF viral vectors}

Before transfection, MSCs predominately showed homogenous population of cells with fibroblast-like morphology. After transfection with retrovirus, cells were slightly shrunken in the beginning but when normal condition was restored, they regained normal morphology (Fig. 2A). Gene expression analysis of SCF in transfected MSCs by RT-PCR showed that the expression level was maximum $(\mathrm{P}<0.01)$ after $48 \mathrm{~h}$ of transfection. The expression started to increase till $48 \mathrm{~h}$ and then decreased subsequently after 1 week, 2 weeks and 3 weeks of transfection (Fig. 2B-C).

Co-culture analysis 
The 15 day co-culture of SCF transfected MSCs and CMs have shown an increase in the number of fused cells as compared to control. Merged images of both cell types showed yellow fluorescence of fused cells (Fig. 3). Quantification of double labeled cells in co-culture was performed through flow cytometry. Results have shown a gradual increase in the number of fused cells as compared to control. Significantly higher number of fused cells is seen in case of SCF transfected MSCs and CMs as compared to control with levels of significance $\mathrm{p}<0.05$ (Fig. 4).

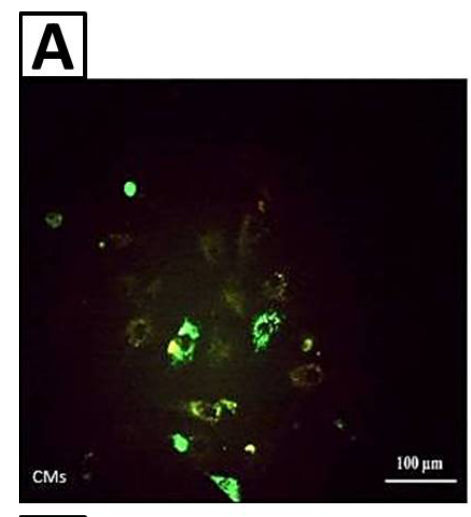

\section{CMs and MSCs}

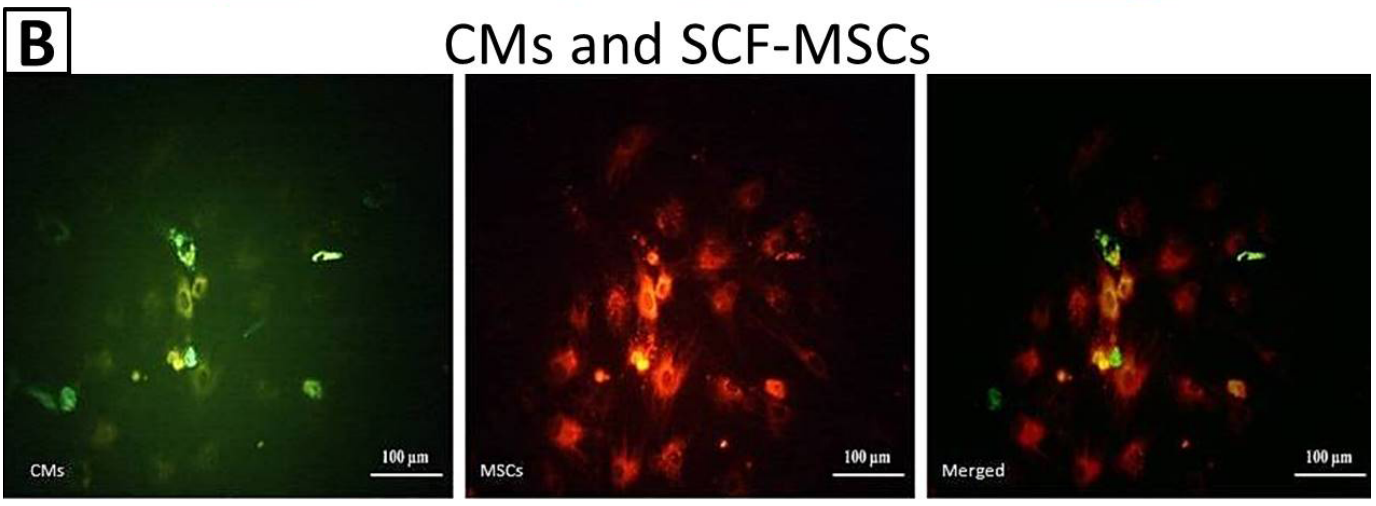

Fig. 3. Co-culture analysis of SCF transfected MSCs with CMs thorugh microscopy: (A) Normal MSCs and normal CMs (control), and (B) SCF transfected MSCs and CMs, in co-culture. MSCs were labeled with PKH26 and CMs with PKH67. Images were taken under fluoresecnt microscope at 10X magnification.
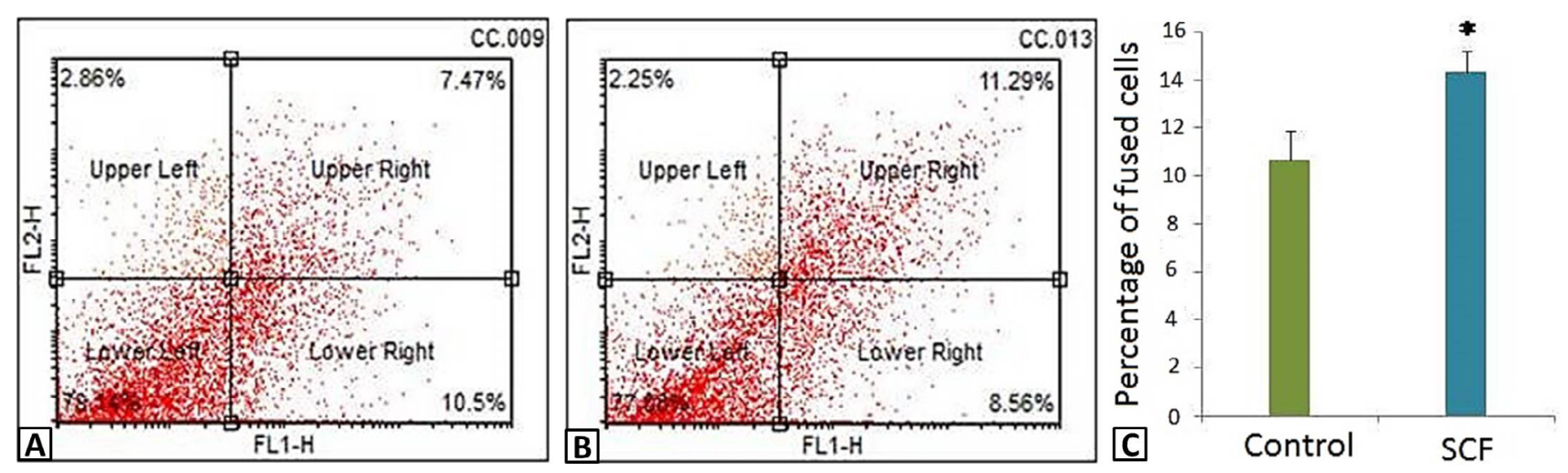

Fig. 4. Co-culture analysis of SCF transfected MSCs with CMs thorugh flow cytometry: (A) Co-culture of normal MSCs and normal CMs (control), and (B) SCF transfected MSCs and CMs. MSCs were labeled with PKH26 and CMs with PKH67. (C) Corresponding bar diagram showing quantitative analysis of double positive cells. Results are expressed as Mean $\pm \operatorname{SEM}(n=3)$. Differences between groups with $\mathrm{P}<0.05$ is considered statistically significant where $* \mathrm{P}<0.05, * * \mathrm{P}<0.01$, and $* * * \mathrm{P}<0.001$. 


\section{DISCUSSION}

Present study successfully set up a co-culturing system of stem cell factor (SCF) transfected mesenchymal stem cells (MSCs) with cardiomyocytes (CMs) to simulate the cell-cell cross talk that may appear beneficial following stem cell transplantation for heart diseases. This in turn may improve differentiation potential MSCs into cardiomyocytes.

Growth factors and cytokines are predominant factors required for trans-differentiation of stem cells into cardiac cells (Psaltis et al., 2008). They are released by cells and play critical role in repair and regeneration of damaged myocardium (Takahashi et al., 2006). Earlier, we have reported the analyses of the mRNA expressions for SCF in DNP-treated and untreated MSCs and CMs. In this study, SCF was upregulated in MSCs following hypoxic stress (Haneef et al., 2014). The response of growth factors varies with the extent of hypoxia and time of re-oxygenation and if crucially monitored, they can be beneficially used against many ischaemic conditions in stem cell-based cellular therapy.

Stem cell factor or c-kit ligand (SCF) binds to its receptor and plays pivotal role in proliferation, survival and migration of stem cells. SCF is important for cardiomyocyte survival after cardiac injury (Kuang et al., 2008). In this study, we assessed the effect of SCF transfected MSCs in terms of their transdifferentiation potential. We analyzed the overexpression of SCF mRNA in control and transfected MSCs. The expression pattern of SCF showed that the expression reached maximum after $48 \mathrm{~h}$ of transfection, and decreased subsequently after 1 week, 2 weeks and 3 weeks of transfection. On the basis of our gene expression result, we selected $48 \mathrm{~h}$ transfected MSCs for further studies.

Large number of data has shown that cytokines and growth factors alone are insufficient to induce transdifferentiation of MSCs into cardiomyocytes and direct cell to cell cross talk is obligatory for differentiation (Perán et al., 2011). To investigate the cell to cell cross talk, we set up a co-culture system between SCF transfected MSCs and CMs. Cell fusion may result in transdifferentiation that can occur in vivo when stem cells are introduced in the infarcted myocardium. We found several double labeled cells after different days in co-culture through fluorescent microscopy and flow cytometry, which is indicative of cell fusion. Some elongated cell projections protruding from different cells indicate that the cells are interacting with each other. This most probably would result in direct cell to cell connections in due course of time. Co-culture studies have shown improved fusion of SCF transfected MSCs with CMs as compared to control, reflected by increase in the number of double labeled cells which appeared in upper right quadrant.

Extrapolating our results, it can be hypothesized that the engineered MSCs stimulate a higher SCF growth factor production, which would induce fusion capabilities between transplanted MSCs and recipient CMs and ultimately induce efficient differentiation of the transplanted MSCs. The exact molecular mechanism involved in the cross talk of two types of cells is not well understood. The fused cells may proliferate and contribute to the regeneration of damaged myocardium and would have the potential to replace damaged heart cells. It is important to determine the contribution of various factors in the fusion process so that a rational basis for the use of these cells for the therapy of cardiac diseases can be determined.

\section{CONCLUSION}

Diseases involving terminally differentiated tissues e.g. coronary artery diseases are a major challenge all over the world as cardiomyocytes have very low proliferation capacity. We conclude from our study that the stem cell factor or c-kit ligand (SCF) enhances the fusogenic abilities of MSCs. SCF plays significant role in proliferation, survival and migration of stem cells. Hence, SCF promotes fusion or transdifferentiation of MSCs into cardiomyocytes. This study emphasizes the role of SCF in MSCs transdifferentiaion and would aid in designing a therapeutic strategy in which SCF transfected MSCs can be used for the treatment of ischemic diseases.

\section{ACKNOWLEDGEMENT}

This work is supported by Higher Education Commission, Pakistan research grant number: 1425. The authors also acknowledge Late Dr. Siddiqua Jamall (Department of Biochemistry, University of Karachi) for her useful contribution in setting up of transfection studies.

\section{Statement of conflict of interest}

The authors have declared no conflict of interests.

\section{REFERENCES}

Abdelwahid, E., Kalvelyte, A., Stulpinas, A., de Carvalho, K.A., Guarita-Souza, L.C. and Foldes, G., 2016. Stem cell death and survival in heart regeneration and repair. Apoptosis, 21: 252-268. https://doi.org/10.1007/s10495-015-1203-4

Burchfield, J.S. and Dimmeler, S., 2008. Role of paracrine factors in stem and progenitor cell mediated cardiac 
repair and tissue fibrosis. Fibrogen. Tissue Repair, 1: 1-11. https://doi.org/10.1186/1755-1536-1-4

Fan, X.L., Zhang, Y., Li, X. and Fu, Q.L., 2020. Mechanisms underlying the protective effects of mesenchymal stem cell-based therapy. Cell. Mol. Life Sci., 77: 2771-2794. https://doi.org/10.1007/ s00018-020-03454-6

Fazel, S., Chen, L., Weisel, R.D., Angoulvant, D., Seneviratne, C., Fazel, A., Cheung, P., Lam, J., Fedak, P.W., Yau, T.M. and Li, R.K., 2005. Cell transplantation preserves cardiac function after infarction by infarct stabilization: Augmentation by stem cell factor. J. Thorac. Cardiovasc. Surg., 130: 1310. https://doi.org/10.1016/j.jtcvs.2005.07.012

Haneef, K., Naeem, N., Khan, I., Iqbal, H., Kabir, N., Jamall, S., Zahid, M. and Salim, A., 2014. Conditioned medium enhances the fusion capability of rat bone marrow mesenchymal stem cells and cardiomyocytes. Mol. Biol. Rep., 41: 3099-4112. https://doi.org/10.1007/s11033-014-3170-1

Herrmann, J.L., Abarbanell, A.M., Weil, B.R., Manukyan, M.C., Poynter, J.A., Brewster, B.J., Wang, Y. and Meldrum, D.R., 2011. Optimizing stem cell function for the treatment of ischemic heart disease. J. Surg. Res., 166: 138-145. https:// doi.org/10.1016/j.jss.2010.05.057

Ioannidou, E., 2006. Therapeutic modulation of growth factors and cytokines in regenerative medicine. Curr. Pharm. Des., 12: 2397. https://doi. org/10.2174/138161206777699007

Keshtkar, S., Azarpira, N. and Ghahremani, M.H., 2018. Mesenchymal stem cell-derived extracellular vesicles: novel frontiers in regenerative medicine. Stem Cell Res. Ther., 9: 63. https://doi.org/10.1186/ s13287-018-0791-7

Kim, K.L., Seo, S., Kim, J.T., Kim, J., Kim, W., Yeo, Y., Sung, J.H., Park, S.G. and Suh, W., 2019. SCF (stem cell factor) and cKIT modulate pathological ocular neovascularization. Arterioscler. Thromb. Vasc. Biol., 39: 2120-2131. https://doi.org/10.1161/ ATVBAHA.119.313179

Kuang, D., Zhao, X., Xiao, G., Ni, J., Feng, Y., Wu, R. and Wang, G., 2008. Stem cell factor/c-kit signaling mediated cardiac stem cell migration via activation of p38 MAPK. Basic Res. Cardiol., 103: 265-273. https://doi.org/10.1007/s00395-007-0690-z

Lachtermacher, S., Esporcatte, B.L., Montalvao, F., Costa, P.C., Rodrigues, D.C., Belem, L., Rabischoffisky, A., Faria-Neto, H.C., Vasconcellos, R., Iacobas, S., Iacobas, D.A., Dohmann, H.F., Spray, D.C., Goldenberg, R.C. and Campos-deCarvalho, A.C., 2010. Cardiac gene expression and systemic cytokine profile are complementary in a murine model of post-ischemic heart failure. Braz. J. Med. biol. Res., 43: 377-389. https://doi. org/10.1590/S0100-879X2010007500014

Mazzoldi, E.L., Pavan, S., Pilotto, G., Leone, K., Pagotto, A., Frezzini, S., Nicoletto, M.O., Amadori, A. and Pastò, A., 2019. A juxtacrine/paracrine loop between $\mathrm{C}$-Kit and stem cell factor promotes cancer stem cell survival in epithelial ovarian cancer. Cell Death Dis., 10: 412. https://doi.org/10.1038/ s41419-019-1656-4

Peran, M., Marchal, J.A., Rodriguez-Serrano, F.,Alvarez, P. and Aranega, A., 2011. Transdifferentiation: why and how. Cell Biol. Int., 35: 373-379. https://doi. org/10.1042/CBI20100445

Psaltis, P.J., Zannettino, A.C., Worthley, S.G. and Gronthos, S., 2008. Concise review: Mesenchymal stromal cells: potential for cardiovascular repair. Stem Cells, 26: 2201-2210. https://doi.org/10.1634/ stemcells.2008-0428

Shim, W.S., Jiang, S., Wong, P., Tan, J., Chua, Y.L., Tan, Y.S., Sin, Y.K., Lim, C.H., Chua, T., The, M., Liu, T.C. and Sim, E., 2004. Ex vivo differentiation of human adult bone marrow stem cells into cardiomyocyte-like cells. Biochem. biophys. Res. Commun., 324: 481-488. https://doi.org/10.1016/j. bbrc.2004.09.087

Smith, M.A., Court, E.L. and Smith, J.G., 2001. Stem cell factor: Laboratory and clinical aspects. Blood Rev., 15: 191-197. https://doi.org/10.1054/ blre.2001.0167

Steven, S., Frenis, K., Oelze, M., Kalinovic, S., Kuntic, M., Jimenez, M.T.B., Vujacic-Mirski, K., Helmstädter, J., Kröller-Schön, S., Münzel, T. and Daiber, A., 2019. Vascular inflammation and oxidative stress: Major triggers for cardiovascular disease. Oxid. Med. cell. Longev., 2019: 7092151. https://doi.org/10.1155/2019/7092151

Takahashi, M., Li, T.S., Suzuki, R., Kobayashi, T., Ito, H., Ikeda, Y., Matsuzaki, M. and Hamano, K., 2006. Cytokines produced by bone marrow cells can contribute to functional improvement of the infracted heart by protecting cardiomyocytes from ischemic injury. Am. J. Physiol. Heart Circ. Physiol., 291: 886-893. https://doi.org/10.1152/ ajpheart.00142.2006

Vertesaljai, M., Piroth, Z., Fontos, G., Andreka, G., Font, G., Szantho, G., Lueff, S., Reti, M., Masszi, T., Ablonczy, L., Juhasz, E.D., Simor, T., Turner, M.S. and Andreka, P., 2008. Drugs, gene transfer, signaling factors: A bench to bedside approach to myocardial stem cell therapy. Heart Fail. Rev., 
13: 227-244. https://doi.org/10.1007/s10741-0079047-9

Wigren, M., Rattik, S., Hultman, K., Björkbacka, H., Nordin-Fredrikson, G., Bengtsson, E., Hedblad, B., Siegbahn, A., Gonçalves, I. and Nilsson, J., 2016. Decreased levels of stem cell factor in subjects with incident coronary events. J. Intern. Med., 279: 180191. https://doi.org/10.1111/joim.12443

Witman, N., Zhou, C., Grote-Beverborg, N., Sahara, M. and Chien, K.R., 2019. Cardiac progenitors and paracrine mediators in cardiogenesis and heart regeneration. Sem. Cell dev. Biol., 100: 29-51. https://doi.org/10.1016/j.semcdb.2019.10.011

Xiang, F.L., Lu, X., Hammoud, L., Zhu, P., Chidiac, P., Robbins, J. and Feng, Q., 2009. Cardiomyocyte- specific overexpression of human stem cell factor improves cardiac function and survival after myocardial infarction in mice. Circulation, 120: 1065-1074. https://doi.org/10.1161/ CIRCULATIONAHA.108.839068

Xie, X.J., Wang, J.A., Cao, J. and Zhang, X., 2006. Differentiation of bone marrow mesenchymal stem cells induced by myocardial medium under hypoxic conditions. Acta Pharmacol. Sin., 27: 1153-1158. https://doi.org/10.1111/j.1745-7254.2006.00436.x

Xu, M., Uemura, R., Dai, Y., Wang, Y., Pasha, Z. and Ashraf, M., 2007. In vitro and in vivo effects of bone marrow stem cells on cardiac structure and function. J. mol. cell. Cardiol., 42: 441-448. https:// doi.org/10.1016/j.yjmcc.2006.10.009 